\title{
A Multilevel Study of Relationships between Leaders' Dark Triad and Employee Burnout: Mediating Role of Perceived Dark Leadership ${ }^{1}$
}

\section{Ufuk BAŞAR iD a}

a Istanbul Ticaret University, Faculty of Business Administration, Department of Business Administration, Istanbul, Turkey. ubasar@ticaret.edu.tr, ufuk-basar@hotmail.com

\begin{tabular}{|c|c|}
\hline ARTICLE INFO & ABSTRACT \\
\hline Keywords: & \multirow{3}{*}{$\begin{array}{l}\text { Purpose - The aim of this research was to determine whether there are relationships between } \\
\text { leaders' dark triad and employee burnout and whether employees' perception of dark leadership } \\
\text { mediates these relationships. }\end{array}$} \\
\hline Leadership & \\
\hline Dark triad & \\
\hline & \multirow{4}{*}{$\begin{array}{l}\text { Design/methodology/approach - For this purpose, surveys were conducted in the Ankara, Istanbul, } \\
\text { Izmir, Bursa, Samsun, Ordu, Antalya, Gaziantep, and Mugla provinces of Turkey in units of } 12 \\
\text { different private security companies. The sample consisted of } 116 \text { leaders and } 494 \text { employees who } \\
\text { reported to those leaders. Because the sample comprised two levels (i.e., individual and group } \\
\text { levels), the data were analyzed through the hierarchical linear modeling technique. }\end{array}$} \\
\hline Dark leadership & \\
\hline Burnout & \\
\hline Hierarchical linear modeling & \\
\hline Received 2 June 2020 & \multirow{4}{*}{$\begin{array}{l}\text { Findings - The findings indicated that there were significant relationships between perceived dark } \\
\text { leadership and employee burnout, between leaders' dark triad and perceived dark leadership, and } \\
\text { between leaders' dark triad and employee burnout. Additionally, perceived dark leadership } \\
\text { mediated the relationships between leaders' dark triad and employee burnout. }\end{array}$} \\
\hline Necerved 2 june 2020 & \\
\hline Revised 2 August 2020 & \\
\hline Accepted 10 September 2020 & \\
\hline Article Classification: & \multirow{2}{*}{$\begin{array}{l}\text { Discussion - This research contributed to the theory by uncovering the mediating role of perceived } \\
\text { dark leadership between dark personality traits of leaders and employee burnout. Additionally, } \\
\text { significant relationships were discovered between research variables through multilevel analyses } \\
\text { that resulted in more robust implications. Moreover, practitioners are able to improve managerial } \\
\text { processes by paying attention to undesired consequences of dark leadership and leaders' dark triad. }\end{array}$} \\
\hline Research Article & \\
\hline
\end{tabular}

\section{Introduction}

Much research has been conducted on burnout among employees. Nevertheless, the phenomenon of burnout remains important in the management literature, as it has significant undesirable consequences for both organizations and employees (Lee \& Ashforth, 1996). Burnout can be defined as a psychological syndrome in which an employee who is constantly exposed to stressors feels depleted of energy and mentally exhausted (Maslach, Schaufeli, \& Leiter, 2001). Studies have revealed that various individual and situational factors lead to burnout (Halbesleben \& Buckley, 2004). However, to my knowledge, the relationship between dark personality traits among leaders and burnout among their subordinates has not yet been fully clarified by empirical studies.

Dark personality traits can be defined with a "dark triad" structure consisting of narcissism, psychopathy, and Machiavellianism (Paulhus \& Williams, 2002). Leaders, like everyone, may have different levels of dark personality traits. In particular, lower-level leaders, such as line managers, have constant interaction with employees in their daily lives at work. As a result, the dark personality traits of these leaders and the behaviors they exhibit around these traits may lead to undesired consequences, such as burnout among employees. Leaders' behaviors exhibited as a product of dark personality traits may result in subordinates perceiving dark leadership. Perceived dark leadership may in turn trigger burnout. Dark leadership can be defined as a phenomenon comprising wearisome, insincere, and tyrannical behaviors of a leader that are displayed to a specific subordinate or subordinates and cause subordinates to get physiological and/or psychological harm (Başar, Sığrl, \& Basım, 2016). Although the link between personality traits and behaviors of dark leaders has

${ }^{1}$ This research was conducted as a part of Ufuk Başar's doctoral dissertation. 
been noted using different definitions in past studies (Ashforth, 1994; Glad, 2002; Rosenthal \& Pittinsky, 2006; Padilla, Hogan, \& Kaiser, 2007; Lipman-Blumen, 2005, 2011; Furnham, Richards, \& Paulhus, 2013; Volmer, Koch, \& Göritz, 2016; Babiak \& Hare, 2006; Mathieu, Neumann, Hare, \& Babiak, 2014; Mathieu \& Babiak, 2015, 2016), to my knowledge, no study has established this relationship with empirical, multilevel research. To fill this gap, this study investigated how leaders' behaviors that were formed around dark personality traits were perceived by employees, what types of results these behaviors had in terms of employee burnout, and whether there was a relationship between the leaders' dark personality traits and burnout among the employees. Because of the undesirable consequences of burnout syndrome for organizations and employees, understanding the factors that lead to burnout may encourage efforts to eliminate these factors in the future. In addition, since leadership is one of the factors directly influencing an organization's effectiveness, success, and well-being, evaluating the results of leaders' dark personality traits in the eyes of subordinates may increase efforts to improve the selection process of organizational leaders. From this point of view, answering the research questions is thought to be important in terms of contributing to the theory, leading future research, guiding practitioners, and improving managerial processes. In this paper, first, the theoretical framework of the research is established, then the research data are analyzed, and finally, the findings are evaluated and discussed in terms of theory and practice.

\section{Theoretical Framework}

\section{Burnout}

Burnout is a psychological syndrome in which an employee who is constantly exposed to stressors feels depleted and mentally exhausted (Maslach et al., 2001). When employees experience constant stress, they react to stressors. This reaction often manifests itself as emotional exhaustion, depersonalization, and diminished sense of personal accomplishment (Maslach \& Jackson, 1986). In some sources, depersonalization is expressed as cynicism, and diminished sense of personal accomplishment is expressed as decreased professional efficacy (Schaufeli, Leiter, Maslach, \& Jackson, 1996). Responses to the factors that cause employees to experience chronic stress constitute the structure of the burnout (Maslach, 1982; Demerouti, Bakker, Nachreiner, \& Schaufeli, 2001). Emotional exhaustion is often the first reaction of employees to factors that cause chronic stress, the most easily recognized symptom of burnout, and a manifestation of employees' mental fatigue due to chronic stress (Maslach, 1982). Depersonalization is characterized by cynical feelings, attitudes, and behaviors (Sarros \& Sarros, 1992). In the organizational context, cynicism is expressed as alienation of employees from the groups, service recipients, and individuals they interact with daily, as well as their work, and through exhibiting negative, indifferent, and disparaging attitudes and behaviors (Breso, Salanova, \& Schaufeli, 2007). A decrease in professional efficacy or sense of personal accomplishment refers to the assessment of employees in terms of the decrease in their competence, productivity, performance, and efficiency in relation to their work, duties and responsibilities. Employees come to this conclusion through self-assessment (Maslach, 1998).

\section{Dark Leadership}

To date, leadership has been explained around a number of virtues, ideals and approaches focusing on favorable leader behaviors and characteristics, such as transformational leadership (Bass, 1985), ethical leadership (Brown, Trevino, \& Harrison, 2005), and authentic leadership (Walumbwa, Avolio, Gardner, Wernsing, \& Peterson, 2008). However, some organizational leaders are far from these ideals and have negative impacts on their subordinates. Consequently, over time, a large amount of research has been conducted to identify leader behaviors that negatively affect subordinates, and various leadership approaches have been developed to explain the dark side of leadership (Bligh, Kohles, Pearce, Justin, \& Stovall, 2007; Schyns \& Schilling, 2013; Başar et al., 2016). These include petty tyranny (Ashforth, 1994), abusive supervision (Tepper, 2000; Yagil, 2005), narcissistic leadership (Glad, 2002; Rosenthal \& Pittinsky, 2006), toxic leadership (Whicker, 1996; Lipman-Blumen, 2005, 2011), bad leadership (Kellerman, 2004), despotic leadership (De Hoogh \& Den Hartog, 2008), downward bullying (Rayner \& Cooper, 1997; Quine, 1999), destructive leadership (Padilla et al., 2007; Bligh et al., 2007), and dark leadership (Başar et al., 2016). Dark leadership refers to wearisome, insincere, and tyrannical behaviors and attitudes that are displayed by a leader to a specific employee or employees and cause those employees to get physiological and/or psychological harm 
(Başar et al., 2016). What these leadership approaches have in common is that they all explain the dark side of leadership (Başar \& Basım, 2018).

\section{Dark Leadership and Burnout}

Dark leadership behaviors have undesirable consequences for both organizations and employees (Ashforth, 1994; Bligh et al., 2007). Such behaviors can be directed to the organization and/or the employees. Burnout is one of the consequences of leaders' dark behaviors toward employees (Yagil, 2006). Wearisome, insincere, and tyrannical behaviors by leaders may lead to a decrease in employees' resources, such as social support, health status, social relations, or the expected return on the resources spent. According to the conservation of resources theory (Hobfoll, 1989), such conditions lead to stress and burnout. In addition, leaders' wearisome, insincere, and tyrannical behaviors are expected to increase job demands, such as work overload, negative environmental conditions, work-family conflict, and emotional needs, and to decrease job resources, such as employees' control over their tasks, opportunities to improve themselves, participation in decision making, receipt of feedback, fairness of rewards, role clarity, opportunities for promotion, task variety, supervisor support, team spirit, and intergroup solidarity. According to the job demands - job resources theory (Halbesleben \& Buckley, 2004; Neveu, 2007; Demerouti et al., 2001), employees burn out when these conditions occur. In the meantime, wearisome, insincere, and tyrannical behaviors may increase employees' workload, reduce or completely eliminate their control over their work, cause unfair distribution of rewards, destroy employees' perceptions of the fairness of management and create appropriate conditions for employees to experience a conflict of values. According to the six areas of worklife theory (Maslach \& Leiter, 1997; Leiter \& Maslach, 1999), these conditions explain employee burnout. Indeed, Yagil (2006), Akman (2016), and Sezici and Güven (2017) found that dark leadership behaviors, under different names and constructs, result in burnout. In light of these evaluations, the first, second, and third hypotheses were developed as follows:

Hypothesis 1: There is a positive relationship between employees' perceived dark leadership and exhaustion.

Hypothesis 2: There is a positive relationship between employees' perceived dark leadership and cynicism.

Hypothesis 3: There is a negative relationship between employees' perceived dark leadership and professional efficacy.

\section{Dark Triad}

Individuals can exhibit functional behaviors as well as nonfunctional behaviors. Dark personality traits explain behavioral tendencies and attitudes that are nonfunctional and perceived as repulsive by others (Hogan \& Kaiser, 2005). Narcissism, psychopathy, and Machiavellianism, which constitute the dark triad structure, are among the socially repulsive personality traits and have attracted the attention of researchers (Paulhus \& Williams, 2002; Furnham et al., 2013).

The word narcissism was inspired by the ancient Greek myth Narcissus, who fell in love with his own image (Raskin \& Terry, 1988; Rosenthal \& Pittinsky, 2006). The phenomenon of narcissism became widely known through Freud's studies (1950, 1957). Indeed, each individual has a certain degree of narcissistic needs. Narcissism entails characteristics such as grandiosity, sense of uniqueness, entitlement, dominance, superiority, and exploitiveness (Pincus et al., 2009).

Psychopathy manifests itself in insensitive and unscrupulous attitudes and behaviors, such as using others for one's own interests, not worrying about others, not caring about rules, not feeling guilt and regret when one's behaviors harm others, and behaving thoughtlessly (Lee \& Ashton, 2005). Most of the work on psychopathy is based on observations made by Cleckley (1988). The main components of psychopathy are impulsivity, callousness, manipulation, exploitation, thrill seeking, remorselessness, low empathy and anxiety (Paulhus \& Williams, 2002).

The development of Machiavellianism as a personality trait was influenced by the philosophy of Niccolo Machiavelli, a philosopher who lived in the 16th century (Furnham et al., 2013). Machiavellianism began to attract the attention of researchers with the work of Christie and Geis (1970). Machiavellianism is defined as an individual's prioritization of his or her own interests and the use of others for this cause. It is characterized by exploiting others for individual interests and purposes, lying, deceiving, persuading, cunning, insensitivity, insincerity, strategic thinking and acting, forming alliances and unethical behavior (Jones \& Paulhus, 2014). 


\section{Leaders' Dark Triad and Employees' Perceived Dark Leadership}

Individuals' behaviors, statements, and attitudes are among the components of personality. There is a relationship between an individual's personality and his or her pattern of behaviors and attitudes. In other words, personality explains the behaviors of individuals (Penney \& Spector, 2002; Hogan \& Kaiser, 2005). Based on this approach, individuals with dark personality traits are expected to exhibit repulsive, unpleasant, and negative attitudes and behaviors. A leader's personality is one of the factors explaining his or her behaviors and, thus, the leadership style he or she applies. Essentially, who one is, indicates how one will lead (Bass, 1985; Hogan \& Kaiser, 2005). Indeed, studies on the dark side of leadership support this point of view. For instance, according to Ashforth (1994), leaders' individual tendencies and beliefs are the precursors of petty tyranny. According to Glad (2002), there is a relationship between the personalities and behaviors of tyrants. Tyrants' personalities are mostly narcissistic and consist of vaingloriousness, lack of self-confidence, and cruelty. According to Rosenthal and Pittinsky (2006), the visions, plans, and actions of narcissistic leaders are parallel to their psychological needs. To Padilla et al. (2007), one of the factors constituting destructive leadership is a leader's personality traits. According to Lipman-Blumen $(2005,2011)$, there is a relationship between the personality traits and behaviors of toxic leaders. The personality traits noted by Lipman-Blumen coincide with those considered dark personality traits. According to Furnham et al. (2013), Volmer et al. (2016), and Furtner, Maran, and Rauthmann (2017), dark personality traits are one of the components of structures that explain the dark side of leadership. Babiak \& Hare (2006), Mathieu et al. (2014), and Mathieu and Babiak (2015) pointed out the relationship between psychopathy and negative behaviors of leaders. To Mathieu and Babiak (2016), leaders with psychopathic personality traits exhibit abusive behaviors. These studies' conclusions indicate that dark personality traits essentially cover tendencies to behave insensitively, insincerely, thoughtlessly, and emotionlessly. Additionally, these traits include deceiving, despising, and exploiting others (Jones \& Paulhus, 2014; Jones \& Weiser, 2014). Therefore, leaders' dark personalities may lead to destructive and negative behaviors for both their subordinates and their organizations. Subordinates who are exposed to destructive, unpleasant, and negative attitudes and behaviors of their leaders are expected to develop dark leadership perception. With this in mind, the fourth hypothesis of the research is as follows:

Hypothesis 4: There is a positive relationship between leaders' dark personality traits and employees' perceived dark leadership.

\section{Leaders' Dark Triad and Employee Burnout}

Leaders' dark personality traits may be regarded as a threat that forms a basis for undesired behaviors resulting in a decrease in employees' resources and nonrepayment of their labor or spent resources. According to the conservation of resources theory, such a situation leads to burnout (Hobfoll, 1989). Similarly, a leader's dark personality traits may be considered one of the factors that feed dark behaviors and, thus, indirectly lead to an increase in the job demands of employees. Additionally, these traits may be perceived as a threat that results in a decrease in employees' job resources. According to the job demands - job resources theory, such a condition leads to burnout as well (Demerouti et al., 2001). Moreover, a leader's dark personality traits may produce undesired consequences, such as an increase in employees' workload and a decrease in their autonomy, causing employees to develop a perception of injustice, lack of support, and value conflict. According to the six areas of worklife theory, these conditions lead to employee burnout (Maslach \& Leiter, 1997; Leiter \& Maslach, 1999). Indeed, Mathieu et al.'s (2014) findings indicate a positive relationship between psychopathic personality traits of leaders and stress experienced by employees. According to the findings of Mathieu and Babiak (2015), there is a positive relationship between leaders' psychopathic personality traits and employees' job dissatisfaction, intention to quit and neglect of work duties. Similarly, according to the findings of Mathieu and Babiak (2016), there is a positive relationship between the psychopathic personality traits of leaders and job dissatisfaction and intention to quit among employees. Gkorezis, Petridou, and Krouklidou (2015) also pointed out the positive relationship between leaders' Machiavellist characteristics and the emotional exhaustion of their subordinates. Volmer et al.'s (2016) findings indicate a positive relationship between the dark personality traits of leaders and emotional exhaustion of their employees. However, all of these studies were at the individual level. In other words, the data were collected from only one sample (i.e., employees), and the personality traits of the leaders were measured through the employees' perceptions. To my knowledge, there has not been a study examining the relationships between leaders' dark personality traits (i.e., narcissism, Machiavellianism, and psychopathy) and employee burnout (i.e., exhaustion, cynicism, and 
decreased professional efficacy) through multilevel research. Nevertheless, the findings obtained in the aforementioned studies and theoretical arguments give an idea of the relationships between dark personality traits among leaders and burnout among their employees that supports the evaluations made so far. Thus, the fifth, sixth, and seventh hypotheses are as follows:

Hypothesis 5: There is a positive relationship between leaders' dark personality traits and exhaustion of employees.

Hypothesis 6: There is a positive relationship between leaders' dark personality traits and cynicism of employees.

Hypothesis 7: There is a negative relationship between leaders' dark personality traits and the professional efficacy of employees.

In addition to these assessments, the possible relationships between leaders' dark personality traits and employee burnout may be explained by employees' perceived dark leadership. To my knowledge, research supporting this view has not previously been performed. However, in light of the evaluations made so far, it is expected that leaders reflect their dark personality traits through undesired attitudes and behaviors and that employees who are exposed to those behaviors perceive dark leadership and eventually burn out. Yukl's (1989) contention that leaders' behaviors mediate the effects of their personality traits supports this view. In fact, in previous sections of this study, theories were posited on the relationships between leaders' dark personality traits and employees' perceived dark leadership, between employees' perceived dark leadership and burnout, and between leaders' dark personality traits and employee burnout. In this context, the final hypothesis is as follows:

Hypothesis 8: Employees' perceived dark leadership mediates the relationship between leaders' dark personality traits and employee burnout.

\section{Method}

\section{Research Design, Universe, and Sample}

This study was carried out in accordance with a cross-sectional research design. The study population consisted of 270845 employees working at organizations in the private security sector in Turkey (GDS, 2018). The sample consisted of 494 employees and 116 line managers to whom these employees reported. The participants were from 12 different organizations located in the Ankara, Istanbul, Izmir, Bursa, Samsun, Ordu, Antalya, Gaziantep, and Mugla provinces of Turkey. The sample represented the population at a 95\% confidence level and \pm 5 confidence interval. The sample was determined through convenience sampling and consisted of two levels (i.e., individual and group). The individual level refers to the employees, and the group level refers to the groups represented by each leader. Therefore, leaders and employees form a nested structure. That is, employees are nested in groups. The smallest group comprises at least 3 subordinates and a line manager. The largest group comprises 9 subordinates and a line manager. The average number of subordinates attached to a line manager is 4 .

Of the 494 employees who made up the individual level, 360 (72.9\%) were men, 134 (27.1\%) were women, 325 $(65.8 \%)$ were married, $169(34.2 \%)$ were single, $68(13.8 \%)$ had a secondary school degree, $164(33.2 \%)$ had a high school degree, 146 (29.6\%) had an associate's degree, $103(20.9 \%)$ had an undergraduate degree, and 13 $(2.6 \%)$ had a graduate degree. Their ages varied between 23 and $49(\chi=33.26, \mathrm{~s}=5.57)$. Their professional experience varied between 1 and 27 years $(\chi=10.97, \mathrm{~s}=5.42)$.

Of the 116 line managers who made up the group level, 94 (81\%) were men, 22 (19\%) were women, 78 (67.2\%) were married, 38 (32.8\%) were single, $9(7.8 \%)$ had a high school degree, $30(25.9 \%)$ had an associate's degree, $53(45.7 \%)$ had an undergraduate degree, and $24(20.7 \%)$ had a graduate degree. Their ages varied between 24 and $55(\chi=35.30, s=7.10)$. Their professional experience varied between 3 and 28 years $(\chi=11.41, s=6.43)$.

\section{Data Collection Instruments}

Two types of questionnaire forms were used in the study. One was for leaders, and the other was for employees who reported to those leaders. The leader questionnaire contained instructions, the dark triad scale, and questions about the participants' demographic information. The employee questionnaire included instructions, the perceived dark leadership scale, the Maslach burnout inventory - general survey, and questions about the participants' demographic information. 


\section{Dark triad scale}

The short dark triad scale, developed by Jones and Paulhus (2014) and adapted to Turkish by Özsoy, Rauthmann, Jonason, and Ardıç (2017), was used. The scale consisted of three factors (i.e., Machiavellianism, narcissism, and psychopathy) and 27 items. A sample item is "I like to use clever manipulation to get my way". Each item was measured over 5 points (1: strongly disagree, 5 : strongly agree). The scale had a sufficient level of construct validity $\left(\chi^{2}=798.22, p=0.000\right.$, d.f. $=302, \chi^{2} /$ d.f. $=2.64, \mathrm{GFI}=0.89$, IFI $=0.96, \mathrm{CFI}=0.96$, RMSEA $=$ 0.06). The Cronbach's $\alpha$ values were found to be $0.94,0.86,0.88$, and 0.88 for the entire scale, Machiavellianism, narcissism, and psychopathy, respectively.

\section{Perceived dark leadership scale}

The perceived dark leadership scale developed by Başar $(2019,2020)$ was used. The scale was developed originally in Turkish. It consisted of three factors (i.e., wearisome, insincere, and tyrannical behaviors) and 17 items. A sample item is "Gives too much work to subordinates". Each item was measured over 5 points (1: never, 5: always). The scale had a sufficient level of construct validity $\left(\chi^{2}=140.12, p=0.009\right.$, d.f. $=103, \chi^{2} /$ d.f. $=$ $1.36, \mathrm{GFI}=0.96, \mathrm{IFI}=0.99, \mathrm{CFI}=0.99, \mathrm{RMSEA}=0.02)$. The Cronbach's $\alpha$ values were found to be $0.95,0.96$, 0.94, and 0.97 for the entire scale, wearisome behaviors, insincere behaviors, and tyrannical behaviors, respectively.

\section{Burnout scale}

The Maslach burnout inventory - general survey (MBI-GS, 1996), developed by Schaufeli et al. (1996) and adapted to Turkish by Mind Garden (2018), which possesses its copyright, was used. It consisted of three factors (i.e., exhaustion, cynicism, and professional efficacy) and 16 items. A sample item is "I feel emotionally drained from my work". Each item was measured over 7 points (0: never, 6: every day). The scale had a sufficient level of construct validity $\left(\chi^{2}=95.01, p=0.480\right.$, d.f. $=95, \chi^{2} /$ d.f. $=1.00, \mathrm{GFI}=0.97, \mathrm{IFI}=1.00, \mathrm{CFI}=1.00$, RMSEA $=0.01$ ). The Cronbach's $\alpha$ values were found to be $0.62,0.95,0.97$, and 0.98 for the entire scale, exhaustion, cynicism, and professional efficacy, respectively. The low $\alpha$ value for the entire scale is considered to be due to the fact that the professional efficacy had a negative relationship with the other factors (i.e., exhaustion and cynicism). Therefore, the values to be considered should be $\alpha$ values of the items that make up each factor because the MBI-GS was not designed for single-factor use.

\section{Research Process}

To test the hypotheses, surveys were conducted in several units of 12 different private security companies operating in the Ankara, Istanbul, Izmir, Bursa, Samsun, Ordu, Antalya, Gaziantep, and Mugla provinces of Turkey between 25 June and 8 October 2018. For this purpose, several security managers who led security operations in a particular facility were visited and informed about the purpose and scope of the research. After the consent of a manager was obtained, a survey was conducted at that facility. First, a leader questionnaire was given to a line manager who wanted to participate in the survey. As the line manager was filling out the questionnaire, the researcher waited for him or her and answered his or her queries. After the line manager returned the completed questionnaire, the researcher met with his or her subordinates. After informing each subordinate about the purpose and scope of the survey, the researcher gave the employee questionnaires to those who wanted to participate in the survey. The employee questionnaires were collected by the researcher on the same day they were distributed. To specify each leader, the researcher coded each leader questionnaire as Leader 1, Leader 2, Leader 3 and so on. Similarly, to match the employees with their line manager and to identify the groups, the researcher coded the employee questionnaires as Group 1, Group 2, Group 3 and so on. By this means, for example, there was only one leader questionnaire with the code Leader 1 and more than one subordinate questionnaire with the code Group 1. In this way, each employee was matched with his or her line manager and groups were identified. Each code was written by the researcher in the upper right-hand corner of a questionnaire after it was received from a participant. After the completed questionnaires were collected from a particular line manager and his or her subordinates, blank questionnaires were distributed to another line manager and his or her subordinates. Each time, only one study was conducted on a particular group. In this way, mixing of the participants in different groups was prevented. 


\section{Data Analysis Strategy}

The hierarchical linear modeling (HLM) technique was used to test the hypotheses. The variables that constituted the individual level were the factors of burnout (i.e., exhaustion, cynicism and professional efficacy) and of perceived dark leadership (i.e., wearisome, insincere and tyrannical behaviors), on which data were collected from employees. The variables that constituted the group level were the factors of the dark triad (i.e., Machiavellianism, narcissism, and psychopathy), on which data were collected from line managers. To analyze the data, two separate files were created with IBM SPSS Statistics Version 23 software. The first file consisted of the data collected from line managers, and the second consisted of the data collected from employees. These files were used by HLM 7 software while testing the hypotheses. The reliability tests of the scales were performed with IBM SPSS Statistics Version 23 software, and confirmatory factor analyses were performed with IBM SPSS AMOS Version 22 software. The correlation values between the variables were calculated with IBM SPSS Statistics Version 23 software.

\section{Findings}

The correlation coefficients between the variables and the means and standard deviations are presented in Table 1. Correlation coefficients could be calculated only between variables of the same level. Each factor of perceived dark leadership had a significant relationship with the factors of burnout. Although they provide insight into the relationships between variables at the same level, these findings are not suitable for evaluating the hypotheses because the group structure was not taken into consideration when calculating the correlation coefficients between the variables at the same level. Moreover, the correlation coefficients between variables at different levels could not be measured by applying the multiple correlation tests. Therefore, the hypotheses were tested in the next step using the HLM technique.

Table 1. Correlations, Means, and Standard Deviations

\begin{tabular}{|c|c|c|c|c|c|c|c|c|c|c|c|c|c|c|}
\hline & & & \multirow{3}{*}{$\chi$} & \multirow{3}{*}{$\mathrm{s}$} & \multirow{3}{*}{$\mathrm{n}$} & \multicolumn{6}{|c|}{ Indıvidual Level Variables } & \multirow{2}{*}{\multicolumn{3}{|c|}{$\begin{array}{c}\text { Group Level Variables } \\
\text { Dark Triad }\end{array}$}} \\
\hline & & & & & & \multicolumn{3}{|c|}{ Perceived Dark Leadership } & \multicolumn{3}{|c|}{ Burnout } & & & \\
\hline & & & & & & $\begin{array}{l}\text { Wearisome } \\
\text { Behaviors }\end{array}$ & $\begin{array}{l}\text { Insincere } \\
\text { Behaviors }\end{array}$ & $\begin{array}{l}\text { Tyrannical } \\
\text { Behaviors }\end{array}$ & Exhaustion & Cynicism & $\begin{array}{l}\text { Professional } \\
\text { Efficacy }\end{array}$ & Machiavellianism & Narcissism & Psychopathy \\
\hline \multirow{6}{*}{ 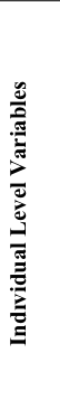 } & \multirow{3}{*}{ 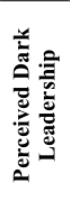 } & $\begin{array}{l}\text { Wearisome } \\
\text { Behaviors }\end{array}$ & 2.32 & 0.96 & 494 & 1 & & & & & & & & \\
\hline & & $\begin{array}{l}\text { Insincere } \\
\text { Behaviors }\end{array}$ & 2.78 & 1.08 & 494 & $0.56^{* * *}$ & 1 & & & & & & & \\
\hline & & $\begin{array}{l}\text { Tyrannical } \\
\text { Behaviors }\end{array}$ & 2.08 & 1.09 & 494 & $0.33^{* * *}$ & $0.58^{* * *}$ & 1 & & & & & & \\
\hline & \multirow{3}{*}{$\stackrel{\Xi}{\Xi}$} & Exhaustion & 2.53 & 0.94 & 494 & $0.70^{* * * *}$ & $0.51^{* * *}$ & $0.49^{* * *}$ & 1 & & & & & \\
\hline & & Cynicism & 2.65 & 1.51 & 494 & $0.58^{* * *}$ & $0.57^{* * *}$ & $0.57^{* * *}$ & $0.54^{* * *}$ & 1 & & & & \\
\hline & & $\begin{array}{l}\text { Professional } \\
\text { Efficacy }\end{array}$ & 2.67 & 1.55 & 494 & $-0.52^{* * *}$ & $-0.51^{* * *}$ & $-0.51^{\cdots *}$ & $-0.50^{* *}$ & $-0.56^{* *}$ & 1 & & & \\
\hline \multirow{3}{*}{ 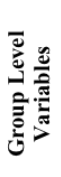 } & \multirow{3}{*}{ 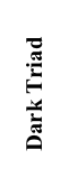 } & Machiavellianism & 3.29 & 0.83 & 116 & & & & & & & 1 & & \\
\hline & & Narcissism & 3.27 & 0.79 & 116 & & & & & & & $0.72^{* * *}$ & 1 & \\
\hline & & Psychopathy & 2.36 & 0.85 & 116 & & & & & & & $0.64^{* * *}$ & $0.59^{* * *}$ & 1 \\
\hline
\end{tabular}

\section{Test of Hypotheses 1, 2, and 3}

For the first and second hypotheses, the dependent variables were the exhaustion and cynicism factors of burnout respectively. For the third hypothesis, the dependent variable was the professional efficacy factor of burnout. For these hypotheses, the independent variables were the factors of perceived dark leadership. To use the HLM technique, it must be statistically confirmed that the dependent variables consist of significant groups, or, in other words, that the dependent variables vary at the group level. The HLM 7 software performs a one-way ANOVA test to check whether this condition is met. For this purpose, null models must be created for each dependent variable. There are no independent variables in null models (Wech \& Heck, 2004; Woltman, Feldstain, MacKay, \& Rocchi, 2012). The null models (i.e., Model 1, Model 2, and Model 3), created for the factors of burnout and results obtained after running the models are presented in Table 2. According to the 
findings, exhaustion, cynicism, and professional efficacy levels were significantly different for each group $\left(x_{1}^{2}\right.$ $=7119.85, x_{2}^{2}=3425.42, x_{3}^{2}=4623.15, p<0.001$ ).

Table 2. Results Obtained After Running Null Models

\begin{tabular}{|c|c|c|c|c|c|}
\hline Models & $\chi^{2}$ & d.f. & $u_{0}\left(\tau_{00}\right)$ & $r\left(\sigma^{2}\right)$ & ICC \\
\hline Model 1 (EXH) & $7119.85^{* * *}$ & 115 & 0.83 & 0.05 & 0.93 \\
\hline Model 2 (CYN) & $3425.42^{* * *}$ & 115 & 1.99 & 0.29 & 0.87 \\
\hline Model 3 (PE) & $4623.15^{* * *}$ & 115 & 2.24 & 0.23 & 0.90 \\
\hline Model 7 (WEA) & $15723.10^{* * * *}$ & 115 & 0.89 & 0.02 & 0.96 \\
\hline Model 8 (INS) & $10225.02^{* * *}$ & 115 & 1.17 & 0.05 & 0.95 \\
\hline Model 9 (TYR) & $42851.56^{* * *}$ & 115 & 1.24 & 0.01 & 0.98 \\
\hline
\end{tabular}

$m p<0,001$

EXH: Exhaustion, CYN: Cynisism, PE: Professional Efficacy, WEA: Wearisome Behaviors, INS: Insincere Behaviors, TYR: Tyrannical Behaviors

Model 1: $E X H_{i j}=\gamma_{00}+u_{0 j}+r_{i j}$

Model 2: $C Y N_{i j}=\gamma_{00}+u_{0 i}+r_{i}$

Model 3: $P E_{i j}=\gamma_{00}+u_{0 j}+r_{i j}$

Model 7: $W E A_{i j}=\gamma_{00}+u_{0 j}+r_{i j}$

Model 8: INS $i j=\gamma_{00}+u_{0 j}+r_{i j}$

Model 9: $T Y R_{i j}=\gamma_{00}+u_{0 j}+r_{i j}$

Following these procedures, Models 4, 5, and 6 were established to reveal the relationships between factors of perceived dark leadership and factors of burnout. The findings obtained after the models were run are presented in Table 3.

Table 3. Results of Hypothesis Tests

\begin{tabular}{|c|c|c|c|c|c|c|c|c|c|}
\hline Models & $\gamma_{00}$ & $\gamma_{01}$ & $\gamma_{02}$ & $\gamma_{03}$ & $\gamma_{10}$ & $\gamma_{20}$ & $\gamma_{30}$ & $\begin{array}{c}r^{2} \\
\text { (Individual level) }\end{array}$ & $\begin{array}{c}r^{2} \\
\text { (Group level) }\end{array}$ \\
\hline Model 4 & $2,47^{* * *}$ & & & & $0.47^{* * *}$ & $0.08^{*}$ & $0.23^{* * * *}$ & 0.14 & \\
\hline Model 5 & $2,60^{* * *}$ & & & & $0.56^{* * *}$ & 0.11 & $0.39^{* * *}$ & 0.06 & \\
\hline Model 6 & $2,82^{* * * *}$ & & & & $-0.58^{* * *}$ & $-0.15^{*}$ & $-0.36^{* * *}$ & 0.08 & \\
\hline Model 10 & $2,35^{* * *}$ & -0.14 & $0.50^{* * *}$ & $0.26^{*}$ & & & & & 0.23 \\
\hline Model 11 & $2,81^{* * *+}$ & $0.67^{* * * *}$ & 0.13 & 0.00 & & & & & 0.33 \\
\hline Model 12 & $2,10^{* * *}$ & 0.18 & 0.18 & $0.65^{* * * *}$ & & & & & 0.46 \\
\hline Model 13 & $2,53^{* * *}$ & 0.00 & $0.48^{* * *}$ & $0.37^{* *}$ & & & & & 0.47 \\
\hline Model 14 & $2,72^{* * *}$ & 0.14 & $0.56^{* *}$ & 0.31 & & & & & 0.25 \\
\hline Model 15 & $2,69^{* * * *}$ & $-0.51^{*}$ & $-0.49^{*}$ & -0.01 & & & & & 0.24 \\
\hline Model 16 & $2,47^{* * * *}$ & -0.02 & 0.15 & $0.36^{* * *}$ & $0.37^{* * *}$ & 0.07 & 0.07 & 0.15 & 0.76 \\
\hline Model 17 & $2,63^{* * *}$ & 0.02 & 0.16 & -0.03 & $0.53^{* * *}$ & 0.10 & $0.36^{* * *}$ & 0.06 & 0.64 \\
\hline Model 18 & $2,78^{* * *}$ & $-0.51^{* *}$ & -0.09 & 0.05 & $-0.62^{* * *}$ & -0.05 & $-0.34^{* * *}$ & 0.07 & 0.66 \\
\hline
\end{tabular}

${ }^{*} p<0,05,{ }^{* *} p<0,01,{ }^{* * *} p<0,001, r^{2}$ : Explained variance

Model 4: $E X H_{i j}=\gamma_{00}+\gamma_{10} * W E A_{i j}+\gamma_{20}{ }^{*} I N S_{i j}+\gamma_{30} * T Y R_{i j}+u_{0 j}+u_{1 i} * W E A_{i j}+u_{2 j} * I N S_{i j}+u_{3 i} * T Y R_{i j}+\gamma_{i j}$

Model 5: $C Y N_{i j}=\gamma_{00}+\gamma_{10}{ }^{*} W E A_{i j}+\gamma_{20}{ }^{*} I N S_{i j}+\gamma_{30} 0^{*} T Y R_{i j}+u_{0 j}+u_{1 j}{ }^{*} W E A_{i j}+u_{2 j}{ }^{*} I N S_{i j}+u_{3 j}{ }^{*} T Y R_{i j}+\gamma_{i j}$

Model 6: $P E_{i j}=\gamma_{00}+\gamma_{10}{ }^{*} W E A_{i j}+\gamma_{20}{ }^{*} I N S_{i j}+\gamma_{30}{ }^{*} T Y R_{i j}+u_{0 j}+u_{1 j} * W E A_{i j}+u_{2 j}{ }^{*} I N S_{i j}+u_{3 j} * T Y R_{i j}+r_{i j}$

Model 10: $W E A_{i j}=\gamma_{00}+\gamma_{01}{ }^{*} M A C_{j}+\gamma_{02} * N A R_{j}+\gamma_{03} * P S Y_{j}+u_{0 j}+r_{i j}$

Model 11: INS $i j=\gamma_{00}+\gamma_{01}{ }^{*} M A C_{j}+\gamma_{02}{ }^{*} N A R_{j}+\gamma_{03} * P S Y_{j}+u_{0 j}+r_{i j}$

Model 12: $T Y R_{i j}=\gamma_{00}+\gamma_{01}{ }^{*} M A C_{j}+\gamma_{02}{ }^{*} N A R_{j}+\gamma_{03}{ }^{*} P S Y_{j}+u_{0 j}+r_{i j}$

Model 13: $E X H_{i j}=\gamma_{00}+\gamma_{01}{ }^{*} M A C_{j}+\gamma_{02}{ }^{*} N A R_{j}+\gamma_{03} * P S Y_{j}+u_{0 j}+\gamma_{i j}$

Model 14: $C Y N_{i j}=\gamma_{00}+\gamma_{01}{ }^{*} M A C_{j}+\gamma_{02}{ }^{*} N A R_{j}+\gamma_{03}{ }^{*} P S Y_{j}+u_{0 j}+r_{i j}$

Model 15: $P E_{i j}=\gamma_{00}+\gamma_{01}{ }^{*} M A C_{j}+\gamma_{02}{ }^{*} N A R_{j}+\gamma_{03}{ }^{*} P S Y_{j}+u_{0 j}+\gamma_{i j}$

Model 16: $E X H_{i j}=\gamma_{00}+\gamma_{01} * M A C_{i}+\gamma_{02}{ }^{*} N A R_{j}+\gamma_{03}{ }^{*} P S Y_{i}+\gamma_{10}{ }^{*} W E A_{i j}+\gamma_{20}{ }^{*} I N S_{i j}+\gamma_{30}{ }^{*} T Y R_{i j}+u_{0 j}+u_{1 j}{ }^{*} W E A_{i j}+u_{2 j}{ }^{*} I N S_{i j}+u_{3 i} * T Y R_{i j}+\gamma_{i j}$

Model 17: $C Y N_{i j}=\gamma_{00}+\gamma_{01}{ }^{*} M A C_{j}+\gamma_{02}{ }^{*} N A R_{j}+\gamma_{03}{ }^{*} P S Y_{i}+\gamma_{10}{ }^{*} W E A_{i j}+\gamma_{20}{ }^{*} I N S_{i j}+\gamma_{30}{ }^{*} T Y R_{i j}+u_{0 j}+u_{1 j}{ }^{*} W E A_{i j}+u_{2 j}{ }^{*} I N S_{i j}+u_{3 j}{ }^{*} T Y R_{i j}+r_{i j}$

Model 18: $P E_{i j}=\gamma_{00}+\gamma_{01}{ }^{*} M A C_{i}+\gamma_{02}{ }^{*} N A R_{j}+\gamma_{03}{ }^{*} P S Y_{j}+\gamma_{10}{ }^{*} W E A_{i j}+\gamma_{20}{ }^{*} I N S_{i j}+\gamma_{30}{ }^{*} T Y R_{i j}+u_{0 j}+u_{1 j} * W E A_{i j}+u_{2 j}{ }^{*} I N S_{i j}+u_{3 j} * T Y R_{i j}+\gamma_{i j}$

EXH: Exhaustion, CYN: Cynisism, PE: Professional Efficacy,

WEA: Wearisome Behaviors, INS: Insincere Behaviors, TYR: Tyrannical Behaviors,

MAC: Machiavellianism, NAR: Narcissism, PSY: Psychopathy

Model 4 was established to reveal the relationships between the factors of perceived dark leadership and exhaustion. The results indicated that there were positive and significant relationships between wearisome behaviors and exhaustion $\left(\gamma_{10}=0.47, p<0.001\right)$, between insincere behaviors and exhaustion $\left(\gamma_{20}=0.08, p<0.05\right)$ and between tyrannical behaviors and exhaustion $\left(\gamma_{30}=0.23, p<0.001\right)$.

Model 5 was established to reveal the relationships between the factors of perceived dark leadership and cynicism. The results indicated that there were positive and significant relationships between wearisome behaviors and cynicism $\left(\gamma_{10}=0.56, p<0.001\right)$ and between tyrannical behaviors and cynicism $\left(\gamma_{30}=0.39, p<\right.$ 0.001). 
Model 6 was established to reveal the relationships between the factors of perceived dark leadership and professional efficacy. According to the findings, there were negative and significant relationships between wearisome behaviors and professional efficacy $\left(\gamma_{10}=-0.58, p<0.001\right)$, between insincere behaviors and professional efficacy $\left(\gamma_{20}=-0.15, p<0.05\right)$, and between tyrannical behaviors and professional efficacy $\left(\gamma_{30}=-\right.$ $0.36, p<0.001)$.

In light of these findings, the first and third hypotheses are supported. However, the second hypothesis is partially supported, because there was no significant relationship between perceived insincere behaviors and cynicism.

\section{Test of Hypothesis 4}

For the fourth hypothesis, the dependent variables were the factors of perceived dark leadership, and the independent variables were the factors of the dark triad. To use the HLM technique, null models (i.e., Model 7, Model 8, and Model 9) were created for each factor of perceived dark leadership. The results obtained after running the models are presented in Table 2. According to the findings, the levels of the perceived wearisome behaviors, insincere behaviors, and tyrannical behaviors were significantly different for each group $\left(x_{7}^{2}=\right.$ $\left.15723.10, x_{8}^{2}=10225.02, x_{9}^{2}=42851.56, p<0.001\right)$.

Following these procedures, Models 10, 11, and 12 were established to reveal the relationships between factors of the dark triad and factors of the perceived dark leadership. The findings obtained after the models were run are presented in Table 3.

Model 10 was established to reveal the relationships between the factors of the dark triad and the perceived wearisome behaviors. The findings indicated that there were positive relationships between narcissism and wearisome behaviors $\left(\gamma_{02}=0.50, p<0.001\right)$ and between psychopathy and wearisome behaviors $\left(\gamma_{03}=0.26, p<\right.$ 0.05).

Model 11 was established to reveal the relationships between the factors of the dark triad and perceived insincere behaviors. The findings indicated that there was a positive and significant relationship only between Machiavellianism and insincere behaviors $\left(\gamma_{01}=0.67, p<0.001\right)$.

Model 12 was established to reveal the relationships between the factors of the dark triad and perceived tyrannical behaviors. The findings indicated that there was a positive and significant relationship only between psychopathy and tyrannical behaviors $\left(\gamma_{03}=0.65, p<0.001\right)$. According to the findings, the fourth hypothesis is partially supported, because significant relationships were found only between some dimensions of the dark triad and some dimensions of perceived dark leadership.

\section{Test of Hypotheses 5, 6, and 7}

For the fifth and sixth hypotheses, the dependent variables were the exhaustion and cynicism factors of burnout respectively. For the seventh hypothesis, the dependent variable was the professional efficacy factor of burnout. For these hypotheses, the independent variables were the factors of the dark triad. Models 13, 14, and 15 were established to reveal the relationships between factors of the dark triad and factors of the burnout. Findings obtained after the models were run are presented in Table 3.

Model 13 was established to reveal the relationships between the factors of the dark triad and exhaustion. The findings indicated that there were positive and significant relationships between narcissism and exhaustion $\left(\gamma_{02}=0.48, p<0.001\right)$ and between psychopathy and exhaustion $\left(\gamma_{03}=0.37, p<0.01\right)$.

Model 14 was established to reveal the relationships between the factors of the dark triad and cynicism. The findings indicated that there was a positive relationship only between narcissism and cynicism $\left(\gamma_{02}=0.56, p<\right.$ $0.01)$.

Model 15 was established to reveal the relationships between the factors of the dark triad and professional efficacy. The findings indicated that there were negative relationships between Machiavellianism and professional efficacy $\left(\gamma_{01}=-0.51, p<0.05\right)$ and between narcissism and professional efficacy $\left(\gamma_{02}=-0.49, p<0.05\right)$. According to the findings, Hypotheses 5 and 6 are partially supported, because significant relationships were found only between some factors of the dark triad and the exhaustion and cynicism factors of burnout. 
Hypothesis 7 is also partially supported, because significant relationships were found only between Machiavellianism and professional efficacy and between narcissism and professional efficacy.

\section{Test of Hypothesis 8}

Certain conditions must be met for a mediation analysis (Baron \& Kenny, 1986). In this study, these conditions included the following: (1) a significant relationship between the independent variable (leaders' dark triad) and the dependent variable (employee burnout), (2) a significant relationship between the independent variable (leaders' dark triad) and the mediating variable (employees' perceived dark leadership), (3) a significant relationship between the mediating variable (employees' perceived dark leadership) and dependent variable (employee burnout), and (4) when the mediating variable (employees' perceived dark leadership) and the independent variable (leader's dark triad) were entered in the analysis together, a significant relationship between the mediating variable (employees' perceived dark leadership) and the dependent variable (employee burnout) persisted, while the relationship between the independent variable (leaders' dark triad) and the dependent variable (employee burnout) either weakened or became insignificant. If this relationship became insignificant, it would be possible to consider full mediation. If the strength of this relationship decreased, then it would be possible to consider partial mediation (Baron \& Kenny, 1986).

The relationships between employees' perceived dark leadership and burnout were tested with the first, second, and third hypotheses, the relationships between the leaders' dark triad and employees' perceived dark leadership were tested with the fourth hypothesis, and the relationships between the leaders' dark triad and employee burnout were tested with the fifth, sixth, and seventh hypotheses. Therefore, at this stage, the dark triad of the leaders and the employees' perceived dark leadership were entered into the analysis as the independent variables, and employee burnout was entered as the dependent variable to test whether the fourth condition of mediation analysis was fulfilled.

In line with that procedure, Models 16, 17, and 18 were established to reveal the relationships between factors of the dark triad, factors of the perceived dark leadership and factors of the burnout. The results obtained after the model was run are presented in Table 3.

Model 16 was established to reveal the relationships between the factors of the dark triad and exhaustion and between the factors of perceived dark leadership and exhaustion. The findings indicated that there were positive relationships between perceived wearisome behaviors and exhaustion $\left(\gamma_{10}=0.37, p<0.001\right)$ and between psychopathy and exhaustion $\left(\gamma_{03}=0.36, p<0.001\right)$.

Model 17 was established to reveal the relationships between the factors of the dark triad and cynicism and between the factors of perceived dark leadership and cynicism. The findings indicated that there were significant and positive relationships between perceived wearisome behaviors and cynicism $\left(\gamma_{10}=0.53, p<\right.$ $0.001)$ and between perceived tyrannical behaviors and cynicism $\left(\gamma_{30}=0.36, p<0.001\right)$.

Model 18 was established to reveal the relationships between the factors of the dark triad and professional efficacy and between perceived dark leadership and professional efficacy. The findings indicated that there were significant and negative relationships between perceived wearisome behaviors and professional efficacy $\left(\gamma_{10}=-0.62, p<0.001\right)$, between perceived tyrannical behaviors and professional efficacy $\left(\gamma_{30}=-0.34, p<0.001\right)$, and between Machiavellianism and professional efficacy $\left(\gamma_{01}=-0.51, p<0.01\right)$. In light of these findings, the mediation relationships between the variables were examined in stages.

In the first stage, the relationship between the mediator variable (perceived dark leadership) and the dependent variable (burnout) was examined, because to consider a possible mediation, when the independent variable (the dark triad) and mediator variable (perceived dark leadership) are entered into the analysis together, there must be a significant relationship between the mediator variable and dependent variable. Significant relationships were identified between perceived wearisome behaviors and each factor of burnout, between perceived tyrannical behaviors and cynicism, and between perceived tyrannical behaviors and professional efficacy (Models 16, 17, and 18), which are presented in Table 3.

In the second stage, which factors of the independent variable (the dark triad) were related to perceived wearisome behaviors and tyrannical behaviors was examined. To do so, the findings obtained to test the fourth hypothesis were considered. Significant relationships were found between narcissism and perceived 
wearisome behaviors (Model 10), between psychopathy and perceived wearisome behaviors (Model 10), and between psychopathy and perceived tyrannical behaviors (Model 12), which are presented in Table 3.

In the third stage, the prior relationships between narcissism and the factors of burnout and between psychopathy and the factors of burnout were examined. For this purpose, the findings obtained to test the fifth, sixth, and seventh hypotheses were considered. Significant relationships were found between narcissism and each factor of burnout and between psychopathy and exhaustion (Models 13, 14, and 15), which are presented in Table 3.

In the fourth stage, the relationships between narcissism and each factor of burnout and the relationship between psychopathy and exhaustion when the independent variable (the dark triad) and the mediator variable (perceived dark leadership) were entered into the analysis together were investigated. For this purpose, the findings obtained to test the eighth hypothesis were examined. It was observed that the relationships between narcissism and each factor of burnout became insignificant (Models 16, 17, and 18) and the strength of the relationship between psychopathy and exhaustion decreased slightly (Model 16, $\gamma_{03}=0.36$, $p<0.001$ ), which is presented in Table 3. In this case, wearisome behaviors fully mediated the relationships between narcissism and exhaustion, between narcissism and cynicism, and between narcissism and professional efficacy. Additionally, wearisome behaviors partially mediated the relationship between psychopathy and exhaustion. Accordingly, the eighth hypothesis is partially supported, because mediation occurred only between certain factors. Figure 1 illustrates how employees' perceived dark leadership mediated the relationship between leaders' dark triad and employee burnout.

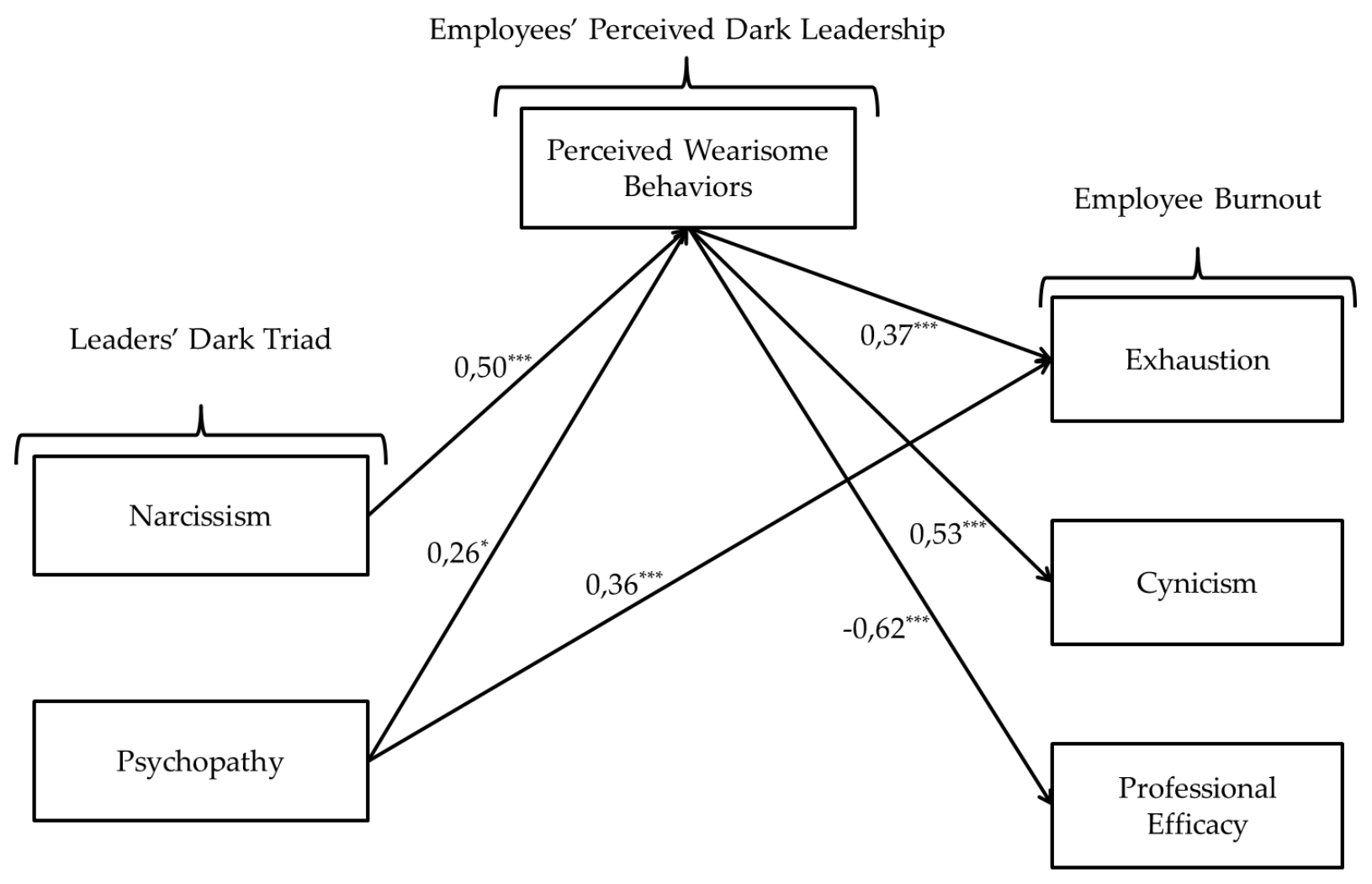

${ }^{4} p<0,05,{ }^{*} p<0,01, "{ }^{*+*} p<0,001$

Figure 1. Mediation Relationship

\section{Discussion and Conclusion}

According to the findings, the participating employees perceived a low level of dark leadership. It is clear that they were mostly exposed to insincere behaviors of their line managers, relatively less exposed to wearisome behaviors and least exposed to tyrannical behaviors. In parallel with these findings, participating employees had low burnout levels. Therefore, it should not be surprising that participating employees evaluated themselves as successful to a certain extent from a professional point of view. They also showed a slight cynical tendency and depersonalization and were exhausted emotionally to a lesser extent. Based on these findings, it can be assumed that the relations of the participating employees with their line managers were mostly 
positive. The facts that the Machiavellianism and narcissism levels of the participating line managers were slightly above the median and that the psychopathy levels were below the median support this assessment. In addition, participating line managers had the most Machiavellist personality trait, relatively less narcissistic personality trait, and the least psychopathic personality trait.

As a result of the analyses, significant relationships were found between employees' perceived dark leadership and burnout. This supports the findings of previous studies investigating the relationships between various leadership models that constitute the dark side of leadership and employee burnout, and the evaluations made within the framework of theories, such as the conservation of resources theory, job demands - job resources theory, and six areas of worklife theory.

According to the findings, there were significant relationships between leaders' dark personality traits and employees' perceived dark leadership in various combinations. The fact that there were no significant relationships between all dark personality traits of the leaders and all factors of perceived dark leadership may be due to individual and contextual differences. When the leaders' dark personality traits that had significant relationships with the employees' perceived dark leadership are considered, it can be concluded that the behaviors defining the dark personality traits overlapped with the employees' perceptions. For example, Machiavellian leaders are expected to exploit their subordinates, lie easily, hold their own interests above all else, and exhibit unethical behaviors for their own purposes. In that regard, the fact that there were positive relationships between the leaders' Machiavellist personality traits and employees' perceived insincere leader behaviors proved the theoretical link between dark personality traits and behaviors empirically (Penney \& Spector, 2002; Hogan \& Kaiser, 2005; Linton \& Power, 2013). Although they are supported by some theoretical evaluations, to my knowledge, the relationships between the leaders' dark personality traits and the employees' perceived dark leadership have not yet been investigated empirically. However, this study tested these theoretical arguments. Therefore, the findings are believed to fill an important gap in the research.

The findings also indicated that there were significant relationships between leaders' dark personality traits and employee burnout in different combinations. The fact that there were significant and positive relationships between narcissistic and psychopathic personality traits of the leaders and exhaustion of the employees may support and improve on Volmer et al.'s (2016) study, because in that study, both the data on employee exhaustion and the data on leaders' personality traits were collected from the employees and analyzed at the individual level. In addition, in Volmer et al.'s (2016) study, burnout was measured in one dimension (i.e., emotional exhaustion). However, in this study, the data on the leaders' personality traits were collected from the line managers, and the data on employee burnout were collected from the subordinates of those line managers and analyzed at multiple levels according to the hierarchical linear modeling technique. Therefore, it is thought that more accurate findings were obtained in this study. Moreover, the findings may also improve on the research of Gkorezis et al. (2015) by investigating and revealing relationships between all the factors of the dark personality traits of leaders and all the factors of employee burnout. Significant relationships found between leaders' dark personality traits and factors of burnout among employees in the multi-level research model appear to have empirically supported the theory.

Another finding that adds value to the research is that the relationship between leaders' dark personality traits and employee burnout was explained by the perceived dark leadership of employees. To my knowledge, this study is the first to establish these relationships operationally. Notably, the relationship between leaders' narcissistic personality trait and employee burnout was fully mediated by leaders' perceived wearisome behaviors. Accordingly, one of the factors revealed to result in employee burnout is leaders' wearisome behaviors. Moreover, leaders' narcissism is among the determinants leading to this result. It was also important to unveil the partial mediating role of leaders' wearisome behaviors between leaders' psychopathy and employees' exhaustion because, based on this finding, it is clear that one of the factors that led to wearisome behaviors by the leaders and thus employee exhaustion was psychopathy among the leaders. In this respect, the findings may contribute to explaining the dark side of leadership and employee burnout.

It is believed that the findings will encourage future studies in that the theoretical model that has been established and tested empirically may be tested in different contexts and professional groups in future research and the results obtained compared with the results of future studies. In addition, the empirical model developed and empirically tested may be improved in future studies. For example, employees' personality 
traits may be added to the model as individual-level variables. Additionally, other personality traits, such as type A personality and locus of control, may be added for leaders as group-level variables. Then, the role of these variables on employee burnout can be investigated in conjunction with leaders' dark personality traits and employees' dark leadership perceptions. Furthermore, the performance of leaders and employees may be measured within the same model in the context of the relationships in question. Thus, more comprehensive findings may be obtained.

The research can also be viewed in terms of cultural characteristics. Turkish society is culturally collectivist, has high power distance, avoids uncertainty and has feminine characteristics (Hofstede, 2001). Additionally, in Turkey, paternalistic leadership is frequently applied by managers. It is also expected by subordinates (Aycan et al., 2000; Paşa, Kabasakal, \& Bodur, 2001). Although paternalistic leadership is perceived by employees as a management style that blends compassion, care, and authority in Turkey and in some other cultures where collectivism is common, such as the Middle East, Latin America, and Asia Pacific, in cultures where individualism is prevalent (i.e., many western cultures), it is viewed with disapproval (Pellegrini \& Scandura, 2008). Therefore, both the social and cultural characteristics of a society and its approved leadership style may have an impact on employees' perceptions of their managers. Thus, in a society where the power distance is high, collectivism is relatively common, and a paternalistic leadership style with authoritarian features is acceptable, some leader behaviors that are considered dark in individualistic societies may be considered normal. In fact, in this study, participants' perceptions of dark leadership were relatively low. Therefore, the role of culture in employees' perceptions of their managers may be investigated in future studies.

For practitioners, the findings may also provide benefits to improve organizations' activities and managerial processes. According to the findings, leaders' wearisome, insincere, and tyrannical behaviors led to employee burnout. In addition, there were significant relationships between leaders' dark personality traits and their dark behaviors. From this point of view, candidates' levels of dark personality traits should be investigated through tests and interviews during recruitment of personnel for managerial positions, and candidates with moderate levels of dark personality traits may be preferred. In addition, awareness of dark leadership and employee burnout among employees and managers who are already working in organizations may be raised through training. In this way, employees and managers can be made aware of the undesired consequences of dark leadership and burnout for both themselves and the organization, so that managers may refrain from wearisome, insincere, and tyrannical behaviors and attitudes. By this means, managerial processes may be improved.

Despite the originality of this research and its significant contributions, it has some limitations. The study was conducted only among private security sector employees, the number of leaders participating in the research was relatively low, and because the study was designed and conducted in accordance with the cross-sectional design, it is not possible to discuss causal relationships between the variables. However, the data were collected from various sources (i.e., line managers and employees attached to each manager), from different organizations operating in the same sector, and at different times (i.e., over a period of approximately three and a half months). Additionally, the data were analyzed at the individual and group levels in accordance with the hierarchical linear modeling technique. That is why, the research lacked certain issues, such as common method variance and multicollinearity. This reinforces the accuracy of the findings. Therefore, despite the limitations, it is thought that this research has various advantages in terms of both the originality of the established theoretical model and the methods applied in the data collection and analysis processes.

\section{References}

Akman, Y. (2016). The relationship between destructive leadership and job burnout: A research on teachers. Journal of Theory and Practice in Education, 12(3), 627-653.

Ashforth, B. (1994). Petty tyranny in organizations. Human Relations, 47(7): 755-778. 
Aycan, Z., Kanungo, R. N., Mendonca, M., Yu, K., Deller, J., Stahl, G., \& Kurshid, A. (2000). Impact of culture on human resource management practices: A 10-country comparison. Applied Psychology: An International Review, 49(1), 192-221.

Babiak, P. \& Hare, R. D. (2006). Snakes in suits: When psychopaths go to work. New York: Harper Collins Publishers.

Baron, R. M. \& Kenny, D. A. (1986). The moderator-mediator variable distinction in social psychological research: Conceptual, strategic and statistical considerations. Journal of Personality and Social Psychology, 51, 1173-1182.

Bass, B. M. (1985). Leadership and performance beyond expectations. New York: Free Press.

Başar, U., Sığrı, Ü., \& Basım, N. (2016). İş yerinde karanlık liderlik. İş ve İnsan Dergisi, 3(2), 65-76.

Başar, U. \& Basım, N. (2018). Paradoksal liderlik modeli. Amme İdaresi Dergisi, 51(3), 121-153.

Başar, U. (2019). Liderin karanlık kişilik özellikleri ile çalışanın tükenmişliği arasındaki ilişkide çalışanın karanlık liderlik algısının aracı rolü: Çok düzeyli bir araştırma (Unpublished doctoral dissertation). Başkent University, Ankara, Turkey.

Başar, U. (2020). İş yerinde karanlık liderlik algısı ölçeği. İstanbul Kent Üniversitesi İnsan ve Toplum Bilimleri Dergisi, 1(1), 70-103.

Bligh, M. C., Kohles, J. C., Pearce, C. L., Justin, J. E., \& Stovall, J. F. (2007). When the romance is over: Follower perspectives of aversive leadership. Applied Psychology: An International Review, 56(4), 528-557.

Breso, E., Salanova, B., \& Schaufeli, W. B. (2007). In search of the "Third Dimension" of burnout: Efficacy or inefficacy. Applied Psychology: An International Review, 56(3), 460-478.

Brown, M. E., Trevino, L. K., \& Harrison, D. A. (2005). Ethical leadership: A social learning perspective for construct development and testing. Organizational Behavior and Human Decision Processes, 97, 117-134.

Christie, R. \& Geis, F. (1970). Studies in Machiavellianism. New York, NY: Academic Press.

Cleckley, H. (1988). The mask of sanity (5 ${ }^{\text {th }}$ ed.). Augusta, GA: Emily S. Cleckley (Original work published in 1941).

De Hoogh, A. H. B., \& Den Hartog, D. N. (2008). Ethical and despotic leadership, relationships with leader's social responsibility, top management team effectiveness and subordinates' optimism: A multimethod study. Leadership Quarterly, 19, 297-311.

Demerouti, E., Bakker, A. B., Nachreiner, F., \& Schaufeli, W. B. (2001). The Job Demands - Resources Model of burnout. Journal of Applied Psychology, 86(3), 499-512.

Fındıklı, M. A., Afacan, C., \& Okan, G. (2018, May). Karanlık liderlik ölçeği: Çalışanların algısı üzerine bir ölçek geliştirme çalışması. Paper presented at 26th Ulusal Yönetim ve Organizasyon Kongresi Bildiriler Kitabı, Trabzon, Turkey.

Freud, S. (1950). Libidinal types. In J. Strachey (Ed.), The standard edition of the complete psychological works of Sigmund Freud (pp. 217-220). London: Hogarth Press. (Original work published in 1931).

Freud, S. (1957). On narcissism: An introduction. In J. Strachey (Ed.), The standard edition of the complete psychological works of Sigmund Freud (73-102). London: Hogarth Press. (Original work published in 1914).

Furnham, A., Richards, S. C., \& Paulhus, D. L. (2013). The Dark Triad of personality: A 10-year review. Social and Personality Psychology Compass, 7(3), 199-216.

Furtner, M. R., Maran, T., \& Rauthmann, J. F. (2017). Dark leadership: The role of leaders' dark triad personality traits. In M. Clark, \& C. Gruber (Eds.), Leader development deconstructed. Annals of theoretical psychology (pp. 75 - 99). Cham: Springer.

GDS (General Directorate of Security) January (2018). <http://sinavsonuc. ozelguvenlik.pol.tr/Teskilat/GenelTeskilatIstatistik.aspx>. 
Gkorezis, P., Petridou, E., \& Krouklidou, T. (2015). The detrimental effect of machiavellian leadership on employees' emotional exhaustion: Organizational cynicism as a mediator. Europe's Journal of Psychology, 11(4), 619-631.

Glad, B. (2002). Why tyrants go too far: Malignant narcissism and absolute power. Political Psychology, 23(1), $1-37$.

Halbesleben, J. R. B., \& Buckley, M. R. (2004). Burnout in organizational life. Journal of Management, 30(6), 859879 .

Hobfoll, S. E. (1989). Conservation of resources: A new attempt at conceptualizing stress. American Psychologist, 44(3), 513-24

Hogan, R., \& Kaiser, R. (2005). What we know about leadership. Review of General Psychology, 9(2), 169 -180.

Jones, D. N., \& Paulhus, D. L. (2014). Introducing the short Dark Triad (SD3): A brief measure of dark personality traits. Assessment, 21(1), 28-41.

Jones, D. N., \& Weiser, D. A. (2014). Differential infidelity patterns among the Dark Triad. Personality and Individual Differences, 57, 20-24.

Kellerman, B. (2004). Bad leadership: What it is, how it happens, why it matters. Boston: Harvard Business Publishing.

Lee, R. T. \& Ashforth, B. E. (1996). A meta-analytic examination of the correlates of the three dimensions of job burnout. Journal of Applied Psychology, 81(2), 123-133.

Lee, K., \& Ashton, M. C. (2005). Psychopathy, machiavellianism, and narcissism in the five-factor model and the HEXACO model of personality structure. Personality and Individual Differences, 38, 1571-1582.

Leiter, M. P., \& Maslach, C. (1999). Six areas of work life: A model of the organizational context of burnout. Journal of Health \& Human Services Administration, 21, 472-489.

Linton, D. K., \& Power, J. L. (2013). The personality traits of workplace bullies are often shared by their victims: Is there a dark side to victims? Personality and Individual Differences, 54, 738-743.

Lipman-Blumen, J. (2005). The allure of toxic leaders: Why we follow destructive bosses and corrupt politicians and how we can survive them. New York: Oxford University Press.

Lipman-Blumen, J. (2011). Toxic leadership: A rejoinder. Representation, 47(3), 331-342.

Maslach, C. (1982). Understanding burnout: Definitional issues in analyzing a complex phenomenon. In W. S. Paine (Eds.), Job stress and burnout: Research, theory and intervention perspectives (pp. 29-40). Beverly Hills: Sage Focus Editions.

Maslach, C., \& Jackson S. E. (1986). Maslach Burnout Inventory manual. Palo Alto, CA: Consulting Psychologists Press,

Maslach, C., \& Leiter, M. P. (1997). The truth about burnout. San Francisco: Jossey-Bass.

Maslach, C. (1998). A multidimensional theory of burnout. In C. L. Cooper (Eds.), Theories of organizational stress (pp. 68-85). Oxford: Oxford University Press.

Maslach, C., Schaufeli, W. B., \& Leiter, M. P. (2001). Job burnout. Annual Review of Psychology, 52, 397-422.

MBI - General Survey - MBI-GS: Copyright @1996 Wilmar B. Schaufeli, Michael P. Leiter, Christina Maslach \& Susan E. Jackson. All rights reserved in all media. Published by Mind Garden, Inc., www.mindgarden.com

Mathieu, C., Neumann, C. S., Hare, R. D., \& Babiak, P. (2014). A dark side of leadership: Corporate psychopathy and its influence on employee well-being and job satisfaction. Personality and Individual Differences, 59, 83-88. 
Mathieu, C., \& Babiak, P. (2015). Tell me who you are, I'll tell you how you lead: beyond the full-range leadership model, the role of corporate psychopathy on employee attitudes. Personality and Individual Differences, 87, 8-12.

Mathieu, C., \& Babiak, P. (2016). Corporate psychopathy and abusive subversion: Their influence on employees' job satisfaction and turnover intentions. Personality and Individual Differences, 91, 102-106.

Mind Garden. (December 2017). <http://www.mindgarden.com/maslach-burnout-inventory/173-mbi-licenseto-reproduce.html>.

Neveu, J. P. (2007). Jailed resources: Conservation of resources theory as applied to burnout among prison guards. Journal of Organizational Behavior, 28, 21-42.

Özsoy, E., Rauthmann, J. F., Jonason, P. K., \& Ardıç, K. (2017). Reliability and validity of Turkish version of Dark Triad Dirty Dozen (DTDD-T), Short Dark Triad (SD3-T) and Single Item Narcissism Scale (SINS-T). Personality and Individual Differences, 117, 11-14.

Padilla, A., Hogan, R., \& Kaiser, R. B. (2007). The toxic triangle: Destructive leaders, susceptible followers, and conducive environments. The Leadership Quarterly, 18, 176-194.

Paşa, S. F., Kabasakal, H., \& Bodur, M. (2001). Society, organizations and leadership in Turkey. Applied Psychology, 50(4), 559-589.

Paulhus, D. L., \& Williams, K. M. (2002). The dark triad of personality: Narcissism, Machiavellianism, and psychopathy. Journal of Research in Personality, 36, 556-563.

Pellegrini, E. K., \& Scandura, T. A. (2008). Paternalistic leadership: A review and agenda for future research. Journal of Management, 34(3), 566-593

Penney, L. M., \& Spector, P. E. (2002). Narcissism and counterproductive work behavior: do bigger egos mean bigger problems? International Journal of Selection and Assessment, 10(1/2): 126-134.

Pincus, A. L., Ansell, E. B., Pimentel, C. A., Cain, N. M., Wright, A. G. C., \& Levy, K. N. (2009). Initial construction and validation of the Pathological Narcissism Inventory. Psychological Assessment, 21(3), 365-379.

Quine, L. (1999). Workplace bullying in NHS community trust: staff questionnaire study. BMJ, 318, 228-232.

Raskin, R., \& Terry, H. (1988). A principle-components analysis of the narcissistic personality inventory and further evidence of its construct validity. Journal of Personality and Social Psychology, 54, 890-902.

Rayner, C., \& Cooper, C. (1997). Workplace bullying: myth or reality - can we afford to ignore it? Leadership $\mathcal{E}$ Organization Development Journal, 18(4), 211-214.

Rosenthal, S. A., \& Pittinsky, T. L. (2006). Narcissistic leadership. The Leadership Quarterly, 17, 617-633.

Sarros, J. C., \& Sarros, A. M. (1992). Social support and teacher burnout. Journal of Educational Administration, 30(1), 55-69.

Schaufeli, W. B., Leiter, M. P., Maslach, C., \& Jackson, S. E. (1996). The MBI-General Survey. In C. Maslach, S. E. Jackson, \& M. P. Leiter (Eds.), Maslach Burnout Inventory manual (pp. 19-26). Palo Alto, CA: Consulting Psychologists Press.

Schyns, B. \& Schilling, J. (2013). How bad are the effects of bad leaders? A meta-analysis of destructive leadership and its outcomes. The Leadership Quarterly, 24, 138-158.

Sezici, E. \& Güven, Ö. Z. (2017). İstismarcı yönetici algısının kaytarma üzerindeki etkisinde duygusal tuikenmenin aracılık rolü: Otel işletmelerinde bir inceleme. Anatolia: Turizm Araştırmaları Dergisi, 28(1), 58-68.

Tepper, B. J. (2000). Consequences of abusive supervision. Academy of Management Journal, 43(2), 178-190.

Volmer, J., Koch, I. K., \& Göritz, A. S. (2016). The bright and the dark side of leaders' Dark Triad traits: Effects on subordinates' career success and well-being. Personality and Individual Differences, 101, 413-418. 
Walumbwa, F. O., Avolio, B. J., Gardner, W. L., Wernsing, T. S. \& Peterson, S. J. (2008). Authentic leadership: Development and validation of a theory-based measure. Journal of Management, 34(1), 89-126.

Wech, B. A. \& Heck, A. L. (2004). An introduction to hierarchical linear modeling for marketing researchers. Marketing Bulletin. 15(Technical Note 1): 1-8.

Whicker, M. L. (1996). Toxic leaders: When organizations go bad. Westport, VA: Quorum Books.

Woltman H., Feldstain, A., MacKay, J. C. \& Rocchi, M. (2012). An introduction to hierarchical linear modeling. Tutorials in Quantitative Methods for Psychology. 8(1), 52-69.

Yagil, D. (2005). Employees' attribution of abusive supervisory behaviors. The International Journal of Organizational Analysis, 13(4), 307-326.

Yagil, D. (2006). The relationship of abusive and supportive workplace supervision to employee burnout and upward influence tactics. Journal of Emotional Abuse, 6(1), 49-65.

Yukl, G. A. (1989). Managerial leadership: A review of theory and research. Journal of Management, 15(2), 251289. 